\title{
De Hipias Menor a Trump: das virtudes do erro (e da mentira) ao erro da pós-verdade
}

\author{
Eduardo Paz Barroso \& Rui Estrada \\ Universidade Fernando Pessoa e LabCom.IFP / Universidade Fernando Pessoa e Citcem \\ E-mail: epb@ufp.edu.pt / restrada@ufp.edu.pt
}

\begin{abstract}
Resumo
Neste ensaio, dividido em três partes, procura-se dis- as consequências e os perigos da pós-verdade para o tinguir o conceito de mentira/manipulação de pós- jornalismo e a informação em particular e para a res verdade. Começando com o diálogo Hípias Menor publica e a democracia em geral.
\end{abstract} de Platão e acabando em Donald Trump, discutimos

Palavras-chave: pós-verdade; manipulação; evidência; democracia.

\begin{abstract}
In this essay, which is divided into three parts, we at- sequences and dangers of post-truth for journalism tempt to distinguish the concept of lie/manipulation and information, in particular, as well as for res puof post-truth. Beginning with Plato's Hippias Minor blica and democracy.
\end{abstract}

and ending with Donald Trump, we discuss the con-

Keywords: post-truth; manipulation; evidence; democracy.

\section{Hipias Menor}

To diálogo de Platão intitulado Hípias Menor, Sócrates confronta o famoso sofista ${ }^{1}$ com 1 uma tese muito controversa do ponto de vista ético ${ }^{2}$ : aquele que mais sabe acerca de um determinado assunto, o que domina melhor esse tópico, é, simultaneamente, o mais bem preparado para mentir.

Verdade e mentira aparecem então como faces da mesma moeda: do ponto de vista técnico (deixemos a ética suspensa), o maior expert sobre uma determinada área é, ao mesmo tempo, o mais habilitado para nos enganar acerca dessa área de especialidade.

Data de submissão: 16-01-2018. Data de aprovação: 12-04-2018.

A Revista Estudos em Comunicação é financiada por Fundos FEDER através do Programa Operacional Factores de Competitividade - COMPETE e por Fundos Nacionais através da FCT - Fundação para a Ciência e a Tecnologia no âmbito do projeto Comunicação, Filosofia e Humanidades (LabCom.IFP) UID/CCI/00661/2013.

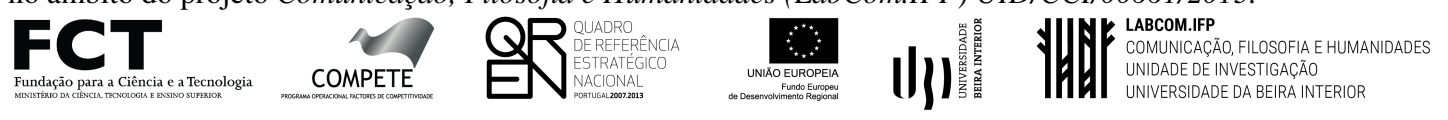

1. Hípias era, de facto, um sofista famoso. Sócrates evoca no diálogo algumas das suas competências: uma memória lendária, predisposição para discutir qualquer assunto, autor de tragédias e ditirambos, fazia, ele próprio, o seu vestuário. Cf. Guthrie, The Sophists, pp. 280-285.

2. Cf. sobre o lugar de Hípias Menor nos diálogos socráticos a 'Introdução' de Maria Teresa Schiappa Azevedo, pp. 9-68. 
Contra Platão e o seu mestre, o dicere in utramque partem (criticado, por exemplo, por Sócrates no Fedro - 265a) e também as antilogias ${ }^{3}$ entram no Hípias Menor como fundamento da argumentação socrática.

Convocando a sabedoria de Hípias em aritmética e cálculo (afirmando o próprio que não tem rival nestas matérias), Sócrates conclui:

\begin{abstract}
Supõe que alguém te perguntava quantos são setecentos vezes três: não eras tu homem para mentir na perfeição e fazer sempre valer as tuas mentiras neste particular, se desejasses mentir e jamais dizer a verdade? Ou um ignorante em aritmética seria capaz de bater-te a palma em mentir, caso tu pretendesses fazê-lo? O facto é que um ignorante que pretendesse mentir estaria arriscado, não poucas vezes, a dizer a verdade sem querer, por causa da sua ignorância, ao passo que tu, sábio como és, se desejasses mentir, conseguirias sempre fazer valer as tuas mentiras? (366e)
\end{abstract}

Na parte final do diálogo, Sócrates assume definitivamente o pensamento antilógico: "De facto, foi também essa a ideia que nos ficou: a alma melhor é obviamente a mais dotada de capacidade e de sabedoria, a que tem mais poder para agir em ambos os sentidos [negrito nosso], o belo e o desonroso, em qualquer tipo de realização..." (376)

Não é nosso interesse neste momento discutir as consequências éticas desta perspectiva socrática; o próprio Sócrates, aliás, põe em causa as suas conclusões na última fala do diálogo (376c). Interessa-nos antes perceber o ponto decisivo da argumentação: aquele que mais conhecimento e evidência tem acerca de determinado assunto é também o mais habilitado para nos mentir. Reparese que aqui, e isso não acontece relativamente à definição de pós-verdade de que falaremos à frente, é decisiva a questão da evidência e do conhecimento.

Acreditamos no engano visto que é alguém credível, competente nesse domínio, que, à luz dessa competência, constrói uma mentira verosímil ou uma manipulação fundamentada, de que é praticamente impossível suspeitar.

Vejamos um exemplo já muito debatido na arena internacional: em 2009, o primeiro-ministro à data da Grã-Bretanha, Gordon Brown, solicita a um alto funcionário, John Chilcot, um relatório sobre a participação da Inglaterra na segunda guerra do Iraque, em 2003.

Em outras partes muito críticas acerca da decisão de entrar na guerra, ao lado dos EUA, tomada por Blair, há a famosa questão das armas de destruição maciça que os serviços de inteligência americanos e ingleses "demonstraram" que o regime de Saddam detinha.

Diz o relatório, publicado em 2016, 13 anos depois do começo da guerra: "É agora claro que a política para o Iraque foi feita com base em informações e avaliações erradas. Informações que não foram questionadas, quando o deviam ter sido (...)" e à frente a propósito do suposto arsenal químico e biológico do Iraque: certas conclusões "foram apresentadas com um grau de certeza que não se justificava (...)" 4

A questão é simples: como pode um cidadão, mesmo bem informado e com sentido crítico, questionar, de forma documentada, as afirmações e as certezas veiculadas pelos serviços secretos

3. Cf. Robinson, Contrasting Arguments an Edition of the Dissoi Logoi, 1984.

4. In Jornal Público, 6 de Julho de 2016. Cf ainda www.theguardian.com/uk-news/2016/jul/06/iraq-inquiry-keypoints-from-the-chilcot-report 
norte-americanos e ingleses? Não pode. Não o pode fazer visto que justamente os serviços que mais sabiam, que mais informação tinham, e que mais credíveis eram para falar do assunto, resolveram mentir-nos descaradamente, condicionando dessa forma a opinião pública e publicada. É irrelevante, para o caso, se foram politizados para o fazer.

Sócrates, do Hípias Menor, está assim de volta: quem mais sabia da verdade induziu-nos no completo logro.

\section{O jornalismo interpretativo}

Num curto, mas muito citado ensaio de 1873, intitulado Acerca da Verdade e da Mentira no Sentido Extramoral, Nietzsche pergunta: "Que é uma palavra? A representação sonora de um estímulo nervoso. (...) como poderíamos nós então dizer «A pedra é dura», como se conhecêssemos a palavra «dura» de outro modo que não apenas como estímulo completamente subjectivo!" (1996, pp. 218-219)

Um pouco à frente, e respondendo agora à questão "Que é então a verdade?", Nietzsche diznos que é um "exército móvel, de metáforas, de metonímias, de antropomorfismos", que transformamos, por meio do esquecimento, em certezas "fixas canónicas e vinculativas". (1996, p. 221)

Começamos com Nietzsche visto que escreve este texto justamente numa altura em que o positivismo é a corrente de pensamento dominante. Ora também o jornalismo se torna permeável a esta busca de objectividade, rigor e neutralidade. A famosa ideia das notícias como "espelho" e a separação absoluta destas com qualquer registo interpretativo ou opinativo é o corolário da fase do jornalismo da objectividade ${ }^{5}$.

Nietzsche contudo tinha razão. Sobretudo a partir da segunda metade do século XX, a epistemologia fundacionalista que orientava grosso modo as ciências sociais e humanas e também a prática do jornalismo é posta em causa pelo pragmatismo ${ }^{6}$, pelo pós-estruturalismo ${ }^{7}$, pelo ressurgimento da retórica e da argumentação ${ }^{8}$.

Vejamos primeiro a questão da linguagem: ao invés de reflectir o mundo exterior (os factos) tal como é em si mesmo, a linguagem cria intersubjectivamente o mundo. Não é neutra, não é transparente, não é objectiva. A famosa teoria da correspondência cede assim lugar à ideia de que a linguagem, as notícias, não reflectem a realidade mas constituem-na. Como diz Davidson:

5. Cf., entre outros, Charnley, "Preliminary Notes on A Study of Newspaper Accuracy", 1936, Scanlon, "A New Approach to Study of Newspaper Accuracy", 1972 e Smith, "The Long Road to Objectivity and Back Again — the Kinds of Truth We Get in Journalism", 1978, que faz esta síntese: "The journalist's profession has brought with it into the late twentieth century a little of the eighteenth-century rationalism into which it was, as an occupation, born. It has grafted onto this a large quantity of Victorian objectivity, of Mr Gradgrind's 'Facts, hard facts', and has attempted, with this scanty and fraying intellectual equipment, to sustain itself through the era of Einstein and Heisbenberg, of rationalised doubts and relativities. Institutionally, the press has continued to require the assistance of a rationale which protects it against the kind of assailant who claims that no knowledge can be certain, still less comprehensive." (p. 197)

6. Cf., entre outros, Rorty, A Filosofia e o Espelho da Natureza, 1979.

7. Cf., entre outros, Cahoone (Ed.), From Modernism to Postmodernism. An Anthology, 1996.

8. Cf., entre outros, Fish, Doing what comes Naturally, 1989 e Perelman/Olbrechts-Tyteca, Traite de L'argumentation, 1988. 
We forget there is no such thing as a language apart from the sounds and marks people make, and the habits and expectations that go with them, 'Sharing a language' with someone else consists in understanding what they say, and talking pretty much the way they do. (2005, p. 131)

$\mathrm{O}$ segundo ponto de Nietzsche diz respeito à questão da verdade. Afastada a possibilidade de a entender como adaequatio rei ad intellectum, o conceito de verdade, numa visão holística, continua perfeitamente operacional e eficaz. Nem de outra forma poderia ser. Mais uma vez a evidência e o conhecimento são decisivos para uma argumentação que reflecte determinadas crenças e valores. Como diz Stich a propósito da escolha de diferentes "processos cognitivos":

A natural suggestion is that rather than looking at how high alternative systems of cognitive process rank on some evaluative standard embedded in our language, we attend instead to the consequences of employing one alternative or the other - more specifically, to the likehood that use of one system or the other will lead to something we value. (1991, p. 130)

Inevitavelmente, os meios de comunicação social reflectem estas escolhas: o jornalismo é narrativo e interpretativo. Mais do que a suposta neutralidade ou objectividade importa a fundamentação robusta das histórias que contamos acerca do mundo e dos outros.

Num ensaio, intitulado «"Upscale" News Audiences and the Transformation of Labour News», Martin explica como, a partir dos anos 70, a perspectiva noticiosa sobre as greves passou a incidir mais sobre os inconvenientes para os cidadãos do que sobre a luta dos trabalhadores propriamente dita (2010, pp. 27-43). É um exemplo, entre outros, de que o jornalismo é orientado e partilha convicções. As notícias "espelho" perdem o sentido.

A concepção de "ritual estratégico" (Tuchman, 1972) adquire actualmente um sentido de ritualização da verdade mediática, sempre necessária para fazer face a uma crise da compreensão. Sem neutralidade (ou pelo menos sem a sua proclamação) não existe inteligibilidade do real

"Os jornalistas têm de ser capazes de invocar algum conceito de objectividade a fim de trabalhar os factos relativos à realidade social." (Tuchman, 1993, p. 75). A forma das notícias, o conteúdo, o modo como os jornalistas vão manusear a narrativa (story) e o tipo de relações mantidas no interior das organizações jornalísticas são, de acordo com a autora, vectores essenciais que criam uma estratégia que permite ao consumidor da notícia formar uma percepção de verdade.

Construir notícias é uma forma de agir que deve ser fiável, credível e autêntica. A assimilação e posterior interiorização dos factos é precedida de uma avaliação ponderada onde o factor impessoalidade é condição necessária a garantir uma separação entre aquilo que o jornalista pensa como indivíduo e cidadão e aquilo que ele relata com base num compromisso profissional de imparcialidade (Tuchman, 1993, p. 79). A perspicácia profissional (news judgement) está no cerne de uma cultura de tipo de defensivo, que considera que os jornalistas possuem uma capacidade de decisão relativamente à selecção dos factos, apoiada na aplicação da técnica dos servidores da notícia (a identificação pessoal e temática, a localização temporal e espacial, a justificação e a descrição). Deste modo eles tendem também a proteger-se contra as pressões de que são alvo. Justificar as palavras e as imagens pelos factos, este é o compromisso editorial que importa considerar. Porém a análise e avaliação desses mesmos factos deve ser equidistante da tentação de confundir desejo e realidade. A relação com o senso comum não é despicienda pois este determina em boa medida 
aquilo que pode ser aceite como facto (Tuchman, 1993. pp. 87-88). O jornalista trabalha por isso com o cepticismo.

De que se trata então quando falamos de senso comum? O cartesianismo alicerça o método no trabalho da dúvida e na capacidade de distinguir as ilusões dos sentidos. Podemos considerar o senso comum compatível com uma ontologia do acontecimento? Ferdinand Alquié, um comentador clássico de Descartes, sublinha: "o pensamento só tem sentido pela verdade, e a verdade só o tem pelo Ser" (Alquié, 1980, p. 90). Em suma o jornalista está diante daquilo que existe, daquilo que é (verdadeiro) e nesse existir que revela a essência dos factos, está ancorado um acontecer, cujo interesse e importância lhe compete aferir. Uma tal aferição nunca poderá rejeitar aquilo que o senso comum também admite como verdadeiro. O resultado do trabalho dos jornalistas, as notícias, são objecto do pensamento. Só é pensável mediaticamente aquilo é admitido por (quase) todos.

\section{Pós verdade e jornalismo}

A contemporaneidade é marcada por alterações profundas no campo dos media determinadas não apenas por razões tecnológicas, pela aceleração do quotidiano alimentada pelo directo, e pela informação em tempo real, mas também, e sobretudo, por uma crise de legitimidade dos jornalistas (Wolton: 1999; Bourdieu: 1977; Halimi: 1997) associada uma falência da credibilidade. Para Halimi, os jornalistas são uma espécie de "novos cães de guarda" de interesses alheios. Com quem almoçam hoje os jornalistas? É também a pergunta que ecoa nas páginas do livro onde se lê, numa perspectiva de conclusão:

Des médias de plus en plus présents, des journalistes de plus en plus dociles, une information de plus en plus medíocre. Longtemps, le désir de transformation sociale continuera de buter sur cet obstacle. Face à un parti non declaré, à une oligarchie dont on ne doit rien attendre, mieux vaut rechercher et encourager les voix dissidents, conscientes du caractere irréversible de leur marginalité médiatique" (Halimi:1997, p.102).

As mudanças discursivas no jornalismo ocorridas nas últimas décadas do século XX levaram o jornalismo a interrogar o seu passado e os seus pressupostos. A zona de confluência entre o público e o privado encontra-se agora sujeita a um escrutínio intenso. Evocar a legitimidade das decisões jornalísticas convocando o apoio da opinião pública, idealizar o jornalista watchdog, qual herói que guarda a democracia, frequentemente traído por um conflito de legitimidades (Correia: 2011), são alguns dos aspectos que importa reavaliar nesta época de "pós verdade". Uma época em que a visibilidade dos discursos políticos não coincide necessariamente com as necessidades e estratégias dos media. O predomínio de materiais informativos gerados por organizações e agregados por processos informáticos de reunião de notícias alteram as regras do jogo jornalístico e os novos meios digitais criam um clima de relativização da verdade.

Uma entrada recente no dicionário de Oxford define a pós-verdade como uma atitude relacionada com e indicativa de circunstâncias em que os factos deixam de ter importância e influência na construção da opinião dos públicos e cedem lugar a apelos e convicções pessoais e emocionais. 
"In this era of post-truth politics, it's easy to cherry-pick data and come to whatever conclusion you desire' some commentators have observed that we are living in a post-truth age" 9 .

A perda de influência dos factos conduz a uma erosão das convicções cívicas e a um desgaste dos princípios em que assentava a autoridade do discurso jornalístico. O desejo transforma-se numa espécie de verdade provisória de acordo com expectativas e conveniências. $\mathrm{O}$ acto de negar a verdade tornou-se tão relevante como o seu contrário. Defender a verdade e demonstrar que esta é o pathos da notícia não é agora indispensável. Numa espécie de miscelânea, as notícias tanto podem ser "verdadeiras" como "falsas", e instala-se uma considerável indiferença. Desde que existam "notícias", as especulações das redes sociais estão garantidas, com a sua lógica derivativa e a sua expansão metonímica, onde brotam justicialismos de cunho populista. A perversa confusão entre "jornalismo e comunicação" ameaça uma prática já de si fragilizada por estrangulamentos económicos e por uma ausência de investidores numa mercadoria informativa que não é rentável, ao contrário da comunicação, que é tendencialmente espectacular, animada e agressiva e polémica, $\log 0$ atrai dinheiro ${ }^{10}$.

Vejamos um exemplo a propósito da tomada de posse de Donald Trump: a conselheira da Presidência, Kellyanne Conway, afirmou num programa de televisão que a Casa Branca tinha a sua própria versão sobre o número de pessoas que foram assistir à cerimónia. Havia uma clara diferença daquilo que revelavam as imagens e das opiniões de especialistas, sendo que existem técnicas utilizadas designadamente pelas forças de segurança que permitem calcular o número de pessoas presentes em manifestações e em grandes aglomerações públicas. Mas para a conselheira de Trump tratava-se de "factos alternativos". Pouco tempo depois Merriam-Webster, uma conceituada editora de dicionários, veio através da sua conta no Twitter recordar a definição daquilo que é um "facto". Mas, segundo a imprensa, desde que Conway tinha proferido tal termo, as buscas pelo vocábulo "facto" aumentaram repentinamente. O senso comum teve necessidade de um consenso sobre aquilo que é um "facto" "11. Nenhum jornalista podia de mote próprio cunhar uma nova definição para alguma coisa tão importante e decisiva.

Como é que uma imagem documenta um facto? Gisèle Freund (1995, pp. 106 - 110) num estudo seminal sobre a relação entre a fotografia e sociedade já havia salientado a relevância deste "alargamento do olhar" e a oposição entre a abstracção da palavra e a objectividade da imagem. Actualmente continua a ser necessário contrapor a imagem àquilo que ela representa e tudo se joga, ainda, no plano da interpretação. Mas o que estava em causa na proclamação de Kellyanne Conway relativamente aos "factos alternativos" parece tratar-se de uma dissidência em relação à objectividade jornalística. No entanto as palavras, a definição de cada uma delas, são sempre importantes para contextualizar aquilo que as imagens mostram. Bem vistas as coisas, um jornalista não pode ser complacente com assessores e spin doctors que moldam a língua ao sabor das conveniências políticas.

9. Cf. https://en.oxforddictionaries.com/definition/post-truth

10. Cf. artigo de Pacheco Pereira, intitulado "O que é um jornal de referência? (E de volta a Marcelo e Trump)", Público, 9 Setembro, 2017.

11. Cf. http://rr.sapo.pt/video/126106/mentiras_ou_factos_alternativos_visao_da_casa_branca_contradiz_o_dicion ario 
Por que motivo a "pós-verdade" se tornou aceitável? Ou pelo menos em que medida. Responder a esta questão reconduz-nos aos deveres dos jornalistas numa época de assumida recusa dos factos, de vazio do conhecimento, em que a verificação e as provas adicionais que os jornalistas buscam foram expelidas para fora do campo noticioso, partilhado agora com especialistas de tradução política, criadores de redundâncias que, mediante o expediente da citação, fornecem alternativas a uma verdade que se fazia entender por causa de um culto no real e na capacidade detida pelas notícias de o construir (numa convocação da conhecida teoria de Molotch e Lester, que chama a atenção para "o trabalho de promover ocorrências ao estatuto de acontecimento público salta das necessidades de acontecimento daqueles que fazem a promoção" in Traquina, 1993, pp. 34-51). As necessidades de acontecimento que emanam dos jornalistas embatem na afirmação de "factos alternativos", em suma numa separação artificial do que é considerado e desconsiderado por actores políticos dos quais o mais hilariante é o Donald Trump que descarta evidências com base em dogmas ideológicos, bem expressos nos seus tweets como aquele em que afirma que "O conceito de aquecimento global foi criado pelos e para os chineses de modo a tornar nãocompetitiva a fabricação de produtos nos EUA" ${ }^{12}$. Ou o recurso às aquisições científicas através de uma operação de politização epistemológica que rasura conclusões inconvenientes. Muitas destas atitudes por parte de poderes sufragados não são novas, mas hoje ameaçam cada vez mais a democracia e devolvem-nos a incerteza sobre o papel do jornalismo na definição da sua identidade. Uma identidade ameaçada, como se não lhe bastasse viver o "estado de excepção" (Agamben, 2010). O autor italiano ao teorizar sobre o pensamento de Carl Schmitt e o processo como se associa a excepcionalidade e a soberania, convoca Santi Romano, um influente jurista que marcou o espaço europeu no período compreendido entre as duas guerras, para quem a necessidade é origem da lei (Agamben, 2010, p. 48). A necessidade do estado de excepção parece agora cruzar-se com a necessidade de uma pós-verdade. Vejamos: "O estado de excepção, enquanto figura da necessidade, apresenta-se assim - a par da revolução e da instauração de facto de um ordenamento constitucional - como uma providência «ilegal», mas perfeitamente «jurídica e constitucional», que se concretiza na produção de novas normas (ou de uma nova ordem jurídica)"(Agamben, 2010p. 49). A pós-verdade pode, e com que moldura, legitimar uma verdade não verdadeira, do mesmo modo que o estado de excepção se constitui como regra, pelo simples facto de uma entidade soberana ficar insatisfeita com o estado das coisas. Por isso regressar, com Rancière, à República de Platão e reconhecer que esta é um falso regime político, "um bazar de constituições, um fato de arlequim, tal como gostam os homens para quem o consumo de prazeres e de direitos é a grande questão" (Rancière, 2006, p. 78). E nessa mesma sequência o consumo de "pós-verdades", ou a constatação da desnecessidade democrática.

\section{Referências}

Agamben, G. (2010). Estado de excepção. Lisboa: Edições 70.

Alquié, F. (1980). A filosofia de Descartes. Lisboa: Editorial Presença.

12. Cf. Felipe Duarte Santos, "Pós-verdade e ciência nos EUA com o Sr. Donald Trump", Público, 5 Janeiro, 2017. Cf. também Aidan White, "Fake News: How the Business of the Digital Age Threatens Democracy", 2017. 
Bauman, Z. \& Bordoni, C. (2016). Estado de crise. Lisboa: Relógio d'Água.

Baudrillard, J. (1995). A ilusão do fim ou a greve dos acontecimentos. Lisboa: Terramar.

Cahoone, L. (ed.). (1996). From modernism to postmodernism. An anthology. Oxford: Blackwell Publishers.

Charnley, M. V. (1936). Preliminary notes on a study of newspaper accuracy. [PDF]. Retirado de http://journals.sagepub.com/doi/pdf/10.1177/107769903601300403

Correia, J.C. (2011). O admirável mundo das notícias. Covilhã: LabCom Books, UBI.

Davidson, D. (2005). Truth, language, and history. Oxford: Clarendon Press.

Fish, S. (1989). Doing what comes naturally. Change, rhetoric, and the practice of theory in literary and legal studies. Oxford: Clarendon Press.

Freund, G. (1995). Fotografia e sociedade. Lisboa: Vega.

Guthrie, W. K. C. (1993). The sophists. Cambridge: Cambride UP.

Halimini, S. (1998). Les nouveaux chiens de garde. Paris: Liber - Raisons d'Agir.

Martin, C. R. (2110). "Upscale" news audiences and the transformation of labour news. In J. Richardson (ed.), Language and journalism (pp. 27-44). New York: Routledge.

Nietzsche, F. (1996). O nascimento da tragédia. Lisboa: Círculo de Leitores.

Molotch, H. \& Lester, M. (1993). As notícias como procedimento intencional: acerca do uso estratégico de acontecimentos de rotina, acidentes e escândalos. In N. Traquina (ed.), Jornalismo: questões, teorias e estórias (pp. 34-51). Lisboa: Vega.

Perelman, C. \& Olbrechts-Tyteca, L. (1988). Traite de l'argumentation. Bruxelles: Editions de l'Université de Bruxelles.

Platão. (1981). Fedro. (Trad. e Notas de P. Gomes). Lisboa: Guimarães \& C. ${ }^{a}$ Editores.

Platão. (1990). Hípias menor. Introdução, versão do grego e notas de Maria Teresa Schiappa de Azevedo. Coimbra: Instituto Nacional de Investigação Científica.

Rancière, J. (2006). O ódio à democracia. Lisboa: Mareantes Editora.

Robinson, T. M. (1984). Contrasting arguments an edition of the dissoi logoi. New Hampshire: Salem, N.H.

Rorty, R. (1979). A filosofia e o espelho da natureza. Lisboa: Publicações Dom Quixote.

Scanlon, T. J. (1972). A new approach to study of newspaper accuracy. [PDF]. Retirado de http://journals.sagepub.com/doi/abs/10.1177/107769907204900322

Smith, A. (1978). The long road to objectivity and back again - the kinds of truth we get in journalism. In A. Smith (ed.), The politics of information (pp. 177-198). London and Basingstoke: The Macmillan Press LTD.

Stich, S. P. (1991). The fragmentation of reason. Cambridge: The MIT Press.

Tuchman, G. (1993). A objectividade como ritual estratégico: uma análise das noções de objectividade dos jornalistas. In N. Traquina (ed.), Jornalismo: questões, teorias e estórias (pp. 74-90). Lisboa: Veja. 
White, A. (2017). Fake news: how the business of the digital age threatens democracy. [PDF]. Retirado de https://ethicaljournalismnetwork.org/fake-news-business-democracy

Wolton, D. (1999). Pensar a comunicação. Lisboa: Difel. 